\title{
Strategies for colorectal cancer screening and post-polypectomy surveillance for young adults under age 50
}

\section{Yoon Suk Jung}

Division of Gastroenterology, Department of Internal Medicine, Kangbuk Samsung Hospital, Sungkyunkwan University School of Medicine, Seoul, Korea

Received: March 24, 2021

Revised: April 2, 2021

Accepted: April 3, 2021

Corresponding author:

Yoon Suk Jung

Division of Gastroenterology,

Department of Internal

Medicine, Kangbuk Samsung

Hospital, Sungkyunkwan

University School of Medicine,

29 Saemunan-ro, Jongno-gu,

Seoul 03181, Korea

Tel: +82-2-2001-8577

E-mail:

ys810.jung@samsung.com

\section{ABSTRACT}

The incidence of colorectal cancer in young adults aged $<50$ years is increasing. In line with these recent trends, it is necessary to pay attention to young-onset colorectal adenoma, a precursor of colorectal cancer. Recent studies have reported that the prevalence of colorectal adenomas in young adults aged $<50$ years is not low. Moreover, it has been reported that the prevalence of advanced colorectal neoplasia (advanced adenoma or colorectal cancer) in young persons aged $<50$ years with clinical risk factors or a positive fecal immunochemical test result is not lower than that in average-risk older persons. In this review, I examined and summarized the prevalence and risk factors of colorectal neoplasia (colorectal adenoma or colorectal cancer) in young adults aged $<50$ years. Considering the results of previous studies, I proposed effective strategies for colorectal cancer screening using clinical risk factors and the fecal immunochemical test, and discussed post-polypectomy surveillance for this age group.

Keywords: Colorectal neoplasms; Young adults

\section{INTRODUCTION}

Colorectal cancer (CRC) is the third most common cancer and the second leading cause of cancer-related deaths worldwide [1]. Current guidelines recommend that people at an average risk for CRC start CRC screening at the age of 50 years [2]. Accordingly, the incidence of CRC in adults over the age of 50 has been decreasing over the past few decades. In contrast, the incidence of CRC in young adults under the age of 50 has increased recently. In South Korea, the incidence of CRC increased by 56\%, 41\%, 39\%, and 30\% in adults aged 30-34, 35-39, 40-44, and 45-49 years, respectively, between 1999 and 2015 [3]. A United States population-based study also demonstrated a significant increase in the incidence of CRC diagnosed in young adults [4]. Furthermore, based on current trends, the authors predict that by 2030 , the incidence rate for colon and rectal cancers will increase by $28 \%$ and $46 \%$, respectively for patients aged 35 to 49 years and by $90 \%$ and $124 \%$, respectively for patients aged 20 to 34 years [4]. 
Given that adults under the age of 50 years comprise the majority of the economically active population, the increase in CRC in these young adults can exert a socioeconomic burden. Moreover, young adults with CRC have been reported to have more aggressive tumor characteristics than older adults [5]. Therefore, it is time to pay attention to CRC and colorectal adenomas, the precursors of CRC, that develop at a young age. In the present review, I aimed to discuss the prevalence and risk factors of colorectal neoplasia (CRN), including colorectal adenoma and CRC, in young adults aged $<50$ years, and propose effective strategies for CRC screening. I also discussed post-polypectomy surveillance for young adults aged $<50$ years by reviewing related studies.

\section{PREVALENCE AND RISK FACTORS OF CRN IN YOUNG ADULTS AGED <50 YEARS}

CRN was defined as CRC or any adenoma, while advanced colorectal neoplasia (ACRN) was defined as CRC or advanced adenoma [6]. Advanced adenoma was defined by the presence of at least one of the following features: $\geq 10 \mathrm{~mm}$ diameter, tubulovillous or villous structure, or high-grade dysplasia [6]. To date, several studies have examined the prevalence of CRN in asymptomatic adults aged $<50$ years; the results are summarized in Table 1. In South Korea, according to the Industrial Safety and Health Law, health screening examinations are required for all employees every year or every other year. As part of a welfare policy, companies often provide employees with comprehensive health screenings, including colonoscopy. Accordingly, although the guidelines recommend starting CRC screening at the age of 50, it is not uncommon for asymptomatic adults under the age of 50 years to undergo colonoscopy screening in Korea. For this reason, most studies on CRN in asymptomatic young adults aged $<50$ years have been conducted in Korea. Since age is the most powerful risk factor for CRN, it is natural that adults

Table 1. Prevalence of colorectal neoplasia in asymptomatic young adults aged $<50$ years

\begin{tabular}{|c|c|c|c|}
\hline Study & CRN & ACRN & CRC \\
\hline Imperiale et al. (2002) [7] & 40-49 years: $3.5 \%$ & 40-49 years: $2.3 \%$ & \\
\hline \multirow[t]{2}{*}{ Byeon et al. (2007) [8] } & 20-39 years: $4.7 \%$ & $<50$ years: $2.0 \%$ & \\
\hline & $40-49$ years: $13.9 \%$ & & \\
\hline Park et al. (2009) [9] & $20-29$ years: $9.4 \%$ & $20-29$ years: $0.0 \%$ & $<50$ years: $0.0 \%$ \\
\hline Hong et al. (2010) [10] & 40-49 years: $17.3 \%$ & 40-49 years: $2.5 \%$ & \\
\hline \multirow[t]{2}{*}{ Chung et al. (2010) [11] } & $30-39$ years: $10.4 \%$ & 30-39 years: $0.8 \%$ & \\
\hline & $40-49$ years: $22.2 \%$ & 40-49 years: $3.0 \%$ & \\
\hline Chang et al. (2014) [12] & $40-49$ years: $13.8 \%$ & 40-49 years:1.7\% & \\
\hline Kwak et al. (2016) [14] & 30-39 years: $12.6 \%{ }^{\mathrm{a})}$ & $30-39$ years: $1.0 \%{ }^{\mathrm{b})}$ & \\
\hline Koo et al. (2017) [15] & $40-49$ years: $26.7 \%$ & 40-49 years: $2.4 \%$ & $40-49$ years: $0.5 \%$ \\
\hline \multirow[t]{2}{*}{ Kim et al. (2017) [16] } & $20-39$ years: $20.5 \%$ & 20-39 years: 4.5\% & $20-39$ years: $0.3 \%$ \\
\hline & $40-49$ years: $27.5 \%$ & $40-49$ years: $6.1 \%$ & $40-44$ years: $0.1 \%$ \\
\hline \multirow[t]{2}{*}{ Kim et al. (2019) [17] } & 20-29 years: $2.9 \%$ & 20-29 years: $0.6 \%$ & $20-29$ years: $0.01 \%$ \\
\hline & 30-39 years: 9.5\% & 30-39 years: 0.9\% & $30-39$ years: $0.02 \%$ \\
\hline \multirow[t]{2}{*}{ Butterly et al. (2021) [18] } & $<40$ years: $6.5 \%$ & $<40$ years: $1.1 \%$ & $<40$ years: $0.0 \%$ \\
\hline & 40-49 years: $16.4 \%$ & 40-49 years: $3.4 \%$ & 40-49 years: $0.3 \%$ \\
\hline
\end{tabular}

CRN, colorectal neoplasia; ACRN, advanced colorectal neoplasia; CRC, colorectal cancer.

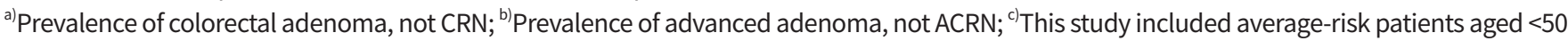
years who had colonoscopies for diagnostic (symptomatic) indications rather than for screening. 
under 50 years of age have a relatively lower prevalence of CRN than those over 50 years of age. Although there have been differences between studies, the prevalence of CRN in adults aged $20-29,30-39$, and $40-49$ years has been reported as $2.4 \%-9.4 \%, 8.0 \%-13.4 \%$, and $3.5 \%-28.1 \%$, respectively, and the prevalence of ACRN in the three age groups has been reported as $0.0 \%-0.6 \%, 0.4 \%-1.0 \%$, and $1.7 \%-6.1 \%$, respectively [7-18]. The prevalence of CRC in adults aged $<50$ years is extremely low.

The risk factors for CRN in asymptomatic adults aged $<50$ years reported in some studies are summarized in Table 2 . The risk factors for CRN in adults under 50 years of age were similar to those in adults over 50 years of age. Most studies have reported that male sex, smoking, obesity, and factors involved in metabolic syndrome are risk factors for CRN or ACRN in young adults aged $<50$ years [10-18].

Recently, two studies, including this one, have developed a model that predicts ACRN in adults under 50 years of age, beyond simply identifying risk factors for ACRN $[19,20]$. In this study, the predicted probability model for ACRN in adults aged 30 to 49 years included age, sex, body mass index (BMI), family history of $C R C$, and smoking habits, as follows: $\mathrm{Y}_{\mathrm{ACRN}}=$ $-8.755+0.080 \times \mathrm{X}_{\text {age }}-0.055 \times \mathrm{X}_{\text {male }}+0.041 \times \mathrm{X}_{\mathrm{BM}}+0.200 \times \mathrm{X}_{\text {family }}$ history_of_CRC $+0.218 \times X_{\text {former_smoker }}+0.644 \times X_{\text {current_smoker }}[19]$. Another study proposed the Young Adult Colorectal Screening score for adults aged $<50$ years, consisting of sex, age, alcohol, smoking, obesity, glucose metabolism abnormality, and family history of CRC, with scores ranging from 0 to 10 [20]. This score was classified into three tiers according to the risk of ACRN (0-4, low risk; 5-7, moderate risk; and 8-10, high risk) [20]. These models may be useful in selecting adults under 50 years of age who require colonoscopy.

\section{CRC SCREENING STRATEGIES FOR YOUNG ADULTS AGED < 50 YEARS}

The concern with screening colonoscopy performed before the age of 50 years is its low cost-effectiveness, because the risk of CRC or ACRN is relatively low in this population. Therefore, we pose the following questions. (1) Should young adults under the age of 50 be screened for CRC? (2) Which persons should be screened for CRC earlier? (3) Which CRC

Table 2. Risk factors of colorectal neoplasia in asymptomatic young adults aged $<50$ years

\begin{tabular}{|c|c|c|}
\hline Study & Risk factors for CRN & Risk factors for ACRN \\
\hline Hong et al. (2010) [10] & $\begin{array}{l}\text { 40-49 years: male sex, abdominal obesity, metabolic } \\
\text { syndrome }\end{array}$ & 40-49 years: abdominal obesity, metabolic syndrome \\
\hline Chung et al. (2010) [11] & $\begin{array}{l}\text { 30-39 years: male sex, smoking }{ }^{\text {a) }} \\
\text { 40-49 years: male sex, smoking }\end{array}$ & $\begin{array}{l}\text { 40-49 years: male sex, smoking, family history of } \\
\text { CRC }^{\text {b) }}\end{array}$ \\
\hline Chang et al. (2014) [12] & & 40-49 years: male sex, smoking, metabolic syndrome \\
\hline Jung et al. (2015) [13] & $\begin{array}{l}\text { 40-49 years: male sex, family history of CRC, smoking, alcohol } \\
\text { intake, metabolic syndrome, obesity, elevated fasting blood } \\
\text { glucose levels, elevated triglyceride levels }\end{array}$ & $\begin{array}{l}\text { 40-49 years: male sex, smoking, metabolic } \\
\text { syndrome, obesity }\end{array}$ \\
\hline Kwak et al. (2016) [14] & 20-39 years: smoking, alcohol consumption ${ }^{c)}$ & \\
\hline Koo et al. (2017) [15] & $\begin{array}{l}\text { 40-49 years: family history of CRC, smoking, and metabolic } \\
\text { syndrome }\end{array}$ & 40-49 years: smoking, metabolic syndrome \\
\hline Kim et al. (2017) [16] & 20-49 years: male sex, obesity & 20-49 years: male sex, smoking, hypertension \\
\hline \multirow[t]{2}{*}{ Kim et al. (2019) [17] } & $\begin{array}{l}\text { 20-29 years: obesity, abdominal obesity, increased levels of } \\
\text { triglycerides, increased blood pressure, increased fasting } \\
\text { blood glucose level }\end{array}$ & $\begin{array}{l}\text { 20-29 years: obesity, abdominal obesity, increased } \\
\text { levels of triglycerides }\end{array}$ \\
\hline & $\begin{array}{l}\text { 30-39 years: smoking, alcohol intake, obesity, abdominal } \\
\text { obesity, male sex metabolic syndrome }\end{array}$ & $\begin{array}{l}\text { 30-39 years: smoking, alcohol intake, obesity, } \\
\text { abdominal obesity }\end{array}$ \\
\hline Butterly et al. (2021) [18] & & 45-49 years: body mass index, smoking \\
\hline
\end{tabular}

CRN, colorectal neoplasia; ACRN, advanced colorectal neoplasia; CRC, colorectal cancer.

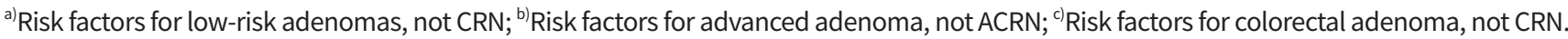


screening modalities should be used for young adults aged $<50$ years? (4) At what age should CRC screening start in young adults aged $<50$ years? To answer these questions, I have conducted several studies, and in the present review, I discuss related studies, including my own studies.

Clinical risk stratification can be useful as a CRC screening strategy for adults under 50 years of age. A Taiwanese study showed that men aged 40 to 49 years with concurrent metabolic syndrome and smoking had a significantly higher prevalence of ACRN than average-risk women aged 50 to 59 years (6.2\% vs. $2.1 \%, P=0.03$ ), and the number of colonoscopies needed to detect one ACRN was 14.6 versus 47.4 , for those respective age groups [12]. These findings may justify a male smoker with metabolic syndrome commencing screening colonoscopy earlier, that is, commencing screening colonoscopy at age 40. One study revealed that the number needed to screen (NNS) to identify one adult patient with ACRN aged 30 to 44 years old with multiple clinical risk factors (including male sex, smoking, metabolic syndrome, and obesity) was higher than that in $\geq 50$-year-old women, whereas NNS for those 45 to 49 years old with the same risk factors was lower than that for $\geq 50$-year-old women (NNS 16.9-22.9 vs. 26.4) [21]. These findings suggest that individuals with clinical risk factors may benefit from commencing screening colonoscopy at 45 years. This is supported by another study that examined the age-specific prevalence of ACRN based on clinical risk factors and fecal immunochemical test (FIT) results in individuals without a family history of CRC [22]. In this study, 1-, 2-, and 1-point scores were assigned to male sex, smoking history, and obesity, respectively, based on the regression coefficient [22]. Even though individuals may have no family history of CRC, the prevalence of ACRN in individuals with $\geq 2$ points (for example, smokers or obese men) rapidly increased as age increased to mid-40s, suggesting that early colonoscopy can be recommended in this age group [22].

In addition to clinical risk stratification, FIT may be a good choice for CRC screening in a young population because of its advantages of non-invasiveness and low cost. Some prior studies support this [23-25]. One study demonstrated that the diagnostic performance of FIT for ACRN in a young population ( $<50$ years) was not inferior to that in the current screening-age population ( $\geq 50$ years). In this study, there were no significant differences in the sensitivity $(22.1 \%$, $17.2 \%$, and $22.0 \% ; P=0.435)$ and specificity $(97.2 \%, 97.4 \%$, and $96.9 \% ; \mathrm{P}=0.344$ ) of FIT for detecting ACRN between the $30-39,40-49$, and $\geq 50$ age groups, respectively [23]. Rather, the 30 to 39 age group had a significantly higher accuracy of
FIT for ACRN $(96.7 \%, P<0.001)$ than the 40 to 49 and $\geq 50$ age groups (95.9\% and 93.8\%, respectively) [23]. These results support the assessment that FIT may be a good test for detecting ACRN in a young population. However, the age at which young adults aged $<50$ years benefit from commencing FIT remains unclear. To determine the age for commencing CRC screening via FIT, another study assessed the risk of ACRN in individuals aged 30-34, 35-39, 40-44, and 45-49 years based on the results of FIT, compared with that of average-risk individuals aged 50 to 59 years [24]. As a result, FIT-positive individuals aged 35-39, 40-44, and 45-49 years had a higher risk of ACRN than average-risk individuals aged 50 to 59 years $(9.7 \%, 7.7 \%, 14.6 \%$ vs. $3.8 \% ; P=0.001, P=$ 0.014 , and $P<0.001$, respectively), whereas FIT-positive individuals aged 30 to 34 years did not $(2.9 \%$ vs. $3.8 \%, P=0.566)$ [24]. These findings suggest that FIT-positive individuals aged 35 to 49 years may benefit from screening colonoscopy, thus justifying the possibility of commencing FIT from the age of 35 years. A Taiwanese study also proposed that screening with FIT could be extended to persons aged 40 to 49 years [25]. In this study, individuals aged 40 to 49 years with positive FIT had a three-times higher CRC risk than those aged 50 to 59 years without FIT, with NNS at 42 and 135 , respectively [25]. Regarding CRC incidence rate, the hazard ratio (HR) for those aged 40-44 or 45-49 years with a positive FIT was 2.3 and 5.7 times higher than the HR for those aged 50-54 years, respectively [25]. In line with these findings, the guideline updated from the American Cancer Society in 2018 recommends starting regular CRC screenings at the age of 45 years [26].

A combination of clinical risk stratification and FIT may be a more effective strategy for CRC screening in young populations. In a recent study, I proposed a two-step evaluation based on clinical risk stratification, followed by FIT [27]. In this study, Asia-Pacific Colorectal Screening (APCS) scores were used. Based on the APCS scoring system, 1-, 2-, and 1-point scores were assigned to male sex, family history of CRC in a first-degree relative (FDR), and current or past smoking history, respectively [28]. FIT-positive individuals 40 to 49 years old with an APCS $\geq 2$ have a higher risk of ACRN than individuals aged $\geq 50$ years with an APCS $\geq 4$ (13.4\% vs. $5.8 \%, P<0.001)$ [27]. Based on these results, a two-step strategy to determine whether early colonoscopy is warranted, follows. Individuals aged 40 to 49 years are first assessed by APCS. If they have an APCS score $\geq 2$, they undergo FIT. Those with positive FIT results undergo early colonoscopy [27].

A FIT result is used clinically as a binary outcome ("negative" 
or "positive") to identify individuals above a predetermined cut-off concentration. However, FIT allows for the quantification of fecal hemoglobin ( $f-H b)$ levels. Several studies have demonstrated that higher $\mathrm{f}-\mathrm{Hb}$ concentrations are significantly associated with a greater risk of ACRN [29-32]. Furthermore, some studies have suggested that risk stratification for ACRN combining $\mathrm{f}-\mathrm{Hb}$ concentration and clinical risk factors can provide better diagnostic accuracy than using FIT binary results alone $[29,30]$. The use of quantitative $\mathrm{f}-\mathrm{Hb}$ concentration in combination with clinical risk factors may be useful for prioritizing individuals who require early colonoscopy.

\section{PROPOSED CRC SCREENING ALGORITHM USING CLINICAL RISK STRATIFICATION AND FIT FOR YOUNG ADULTS AGED $<50$ YEARS}

Considering the results of previous studies and my studies, I propose a CRC screening algorithm using clinical risk stratification and FIT for young adults aged $<50$ years (Fig. 1). Clinical risk stratification is the most easily available modality in a clinical setting. Smoking history can be easily checked by listening to a past history, and obesity can be easily confirmed by measuring the patient's height and weight. Metabolic syndrome can also be confirmed by medical history. Therefore, clinical risk stratification using risk factors for CRN was first used in the proposed CRC screening algorithm. Clinical risk factors for CRN include male sex, smoking, obesity, metabolic syndrome, and family history of CRC in an FDR.

The proposed algorithm is described in detail as follows.
Individuals aged 40 to 49 years with clinical risk factors (i.e., high risk) undergo early colonoscopy, while individuals aged 40 to 49 years without clinical risk factors (i.e., low risk) undergo FIT, and then, FIT-positive individuals undergo colonoscopy. Individuals aged $<40$ years without clinical risk factors (i.e., low risk) do not need to be screened for CRC. However, individuals aged 35 to 39 years with clinical risk factors (i.e., high risk) undergo FIT, and then, FIT-positive individuals undergo colonoscopy. Individuals with multiple clinical risk factors may benefit from more aggressive CRC screening.

\section{POST-POLYPECTOMY SURVEILLANCE FOR YOUNG ADULTS AGED < 50 YEARS}

Since the target age for screening colonoscopy is over 50 years, the current guidelines for surveillance after polypectomy are tailored to persons $\geq 50$ years old. Currently, there are no specific recommendations for surveillance after removal of colorectal adenomas in young patients $<50$ years of age. It has been reported that there are marked differences in recommendations for surveillance for young patients with colorectal adenomas among clinicians [33]. These differences are not surprising given that there are no specific recommendations for the surveillance of young-onset colorectal adenomas. The guidelines recommend a repeat colonoscopy in 5 to 10 years for patients with low-risk adenomas (1-2 non-advanced adenomas, $<10 \mathrm{~mm}$ in size) and 3 years for patients with high-risk adenomas (advanced adenoma or $\geq 3$ adenomas) [6,34]. These low- and high-risk groups were stratified based on the probability of developing metachro-

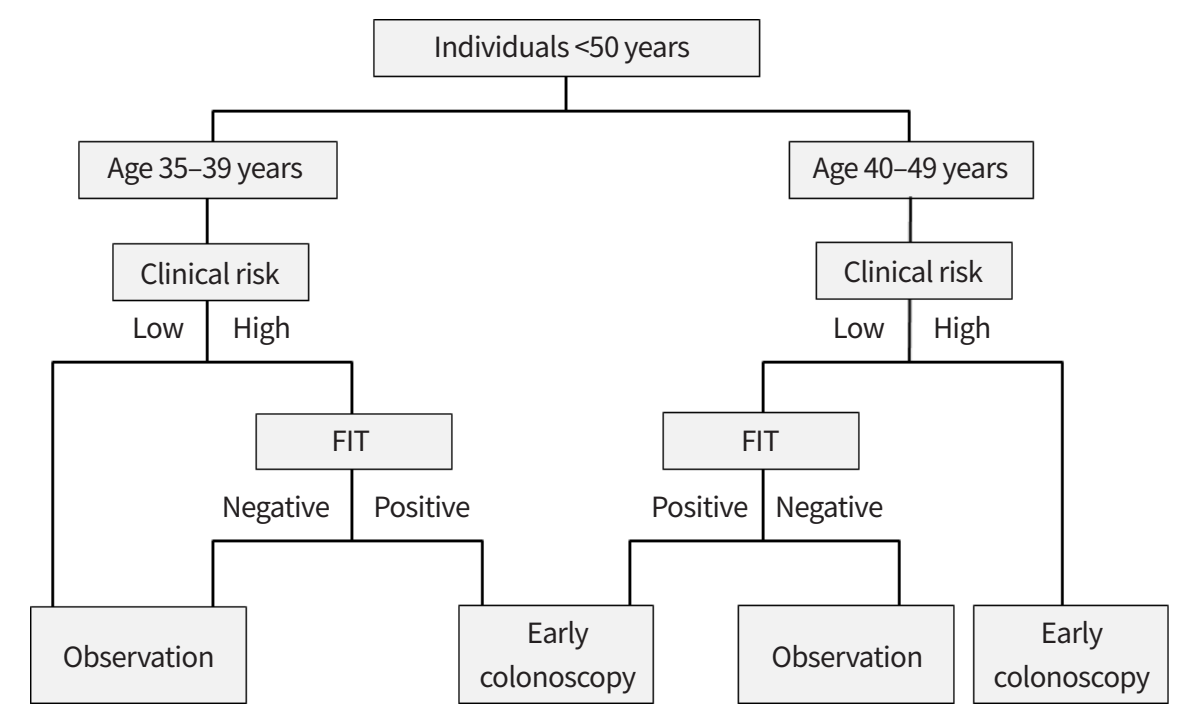

Fig. 1. Proposed colorectal cancer screening algorithm for young adults aged $<50$ years. FIT, fecal immunochemical test. 
nous ACRN. However, these guidelines are based on the findings of studies conducted in patients aged $\geq 50$ years. It remains unclear whether it is appropriate to apply these guidelines equally to young adults aged $<50$ years.

To date, several studies have investigated the risk of metachronous ACRN in patients aged $<50$ years with colorectal adenoma removed. In a pooled analysis of eight prospective studies including 9,167 patients with previously resected colorectal adenomas, patients aged $<40$ years (adjusted odds ratio [aOR], $0.41 ; 95 \%$ confidence interval [Cl], 0.17 to 0.94 ) and those aged 40 to 49 years (aOR, $0.67 ; 95 \% \mathrm{Cl}, 0.48$ to 0.93) had a lower risk of metachronous ACRN compared to those aged 50 to 59 years [35]. My previous study involving 10,014 patients also demonstrated that after high-risk adenoma removal, the 3-year risk of metachronous ACRN in patients aged $30-39$ and $40-49$ years was lower than in those aged $\geq 50$ years $(1.9 \%$ and $3.6 \%$ vs. $8.1 \% ; P<0.001$ and $\mathrm{P}=0.008$, respectively). After low-risk adenoma removal, the 5-year risk of metachronous ACRN in those aged 30-39 and $40-49$ years was lower than in those aged $\geq 50$ years $(2.8 \%$ and $3.3 \%$ vs. $5.9 \% ; P=0.010$ and $P=0.031$, respectively) [36]. These two studies suggest that the post-polypectomy surveillance colonoscopy interval may be extended for patients under 50 years of age than in patients over 50 years of age. This suggestion should be limited to young patients without genetic syndromes, such as familial adenomatous polyposis or hereditary nonpolyposis CRC.

However, some studies have shown inconsistent results with the two studies mentioned above. In a Korean multicenter cohort study, the risk of metachronous ACRN did not differ between patients aged 20 to 49 years and those aged 50 to 54 years [37]. More specifically, in the baseline high-risk adenoma group ( $n=840$ ), the 3-year risk of metachronous ACRN was $10.7 \%$ in patients aged 20 to 49 years and $8.9 \%$ in those aged 50 to 54 years $(P>0.1)$. Furthermore, and in the baseline low-risk adenoma group $(n=1,869)$, the 5 -year risk of metachronous ACRN was $4.9 \%$ in those aged 20 to 49 years and $5.1 \%$ in those aged 50 to 54 years $(P>0.1)$ [37]. A case-control study in the United States also reported a similar risk of metachronous ACRN in patients aged 19 to 40 years $(n=128)$ and 50 to 84 years $(n=123)$ (older patients vs. younger patients: $\mathrm{HR}, 1.3 ; 95 \% \mathrm{Cl}, 0.5$ to $3.0 ; \mathrm{P}=0.58$ ) [38]. In another United States cohort study, the risk of metachronous ACRN in the 40 to 49 years age group $(n=1,036)$ was similar to that in the 50 to 59 years age group $(n=5,238)$ [39]. When compared with the $\geq 60$ years age group ( $n=5,813$, reference), similar risks were found in the 40 to 49 years age group (aOR,
$0.61 ; 95 \% \mathrm{Cl}, 0.41$ to 0.92 ) and the 50 to 59 years age group (aOR, $0.71 ; 95 \% \mathrm{Cl}, 0.58$ to 0.86) [39]. Lastly, an Israeli study compared the risk of metachronous ACRN in younger patients ( $<50$ years, $n=116$ ) and older patients ( 50 to 74 years, $\mathrm{n}=261$ ) [40]. In this study, after advanced adenoma removal, the 3-year risk of metachronous ACRN was $8.3 \%$ and $7.7 \%$ in those aged $<50$ and $50-74$ years, respectively $(P=0.885)$, and after low-risk adenoma removal, the 5-year risk of metachronous ACRN was $8.9 \%$ and $13.3 \%$ in those aged $<50$ and 50 74 years, respectively $(P=0.409)$ [40]. These four studies suggest that the intervals recommended in the current post-polypectomy surveillance guidelines for adults over 50 years of age may be appropriate for younger adults under 50 years of age [37-40]. Taken together, given the various results from previous studies, more research focused on young-onset colorectal adenoma is needed to determine the optimal surveillance interval for young adults aged $<50$ years.

\section{CONCLUSION}

The incidence of CRC in young adults aged $<50$ years has been on the rise in recent years. The prevalence of colon adenoma, a precursor of CRC, in this age group was also not negligible. The risk factors for CRN in young adults under the age of 50 are male sex, smoking, obesity, and metabolic syndrome, as in those over 50 years of age. Age and clinical risk factors can be considered when selecting CRC screening strategies (FIT or colonoscopy). Early colonoscopy may be beneficial in adults over the age of 40 with clinical risk factors or those over the age of 35 years with a positive FIT result. A combination of $\mathrm{f}-\mathrm{Hb}$ concentration and clinical risk factors may be more effective for stratifying the risk for ACRN, and it may also be more useful for prioritizing persons who need early colonoscopy. Given that previous studies have reported that the risk of metachronous ACRN in young patients aged $<50$ years with colorectal adenoma removed was lower than or similar to those aged $\geq 50$ years, the surveillance intervals after polypectomy for young patients aged $<50$ years may not need to be shorter than those recommended in current guidelines focused on those aged $\geq 50$ years.

\section{CONFLICTS OF INTEREST}

No potential conflict of interest relevant to this article was reported. 


\section{ORCID}

Yoon Suk Jung https://orcid.org/0000-0002-1963-7170

\section{AUTHOR CONTRIBUTIONS}

Conception or design: YSJ.

Acquisition, analysis, or interpretation of data: YSJ.

Drafting the work or revising: YSJ.

Final approval of the manuscript: YSJ.

\section{REFERENCES}

1. Wong MC, Ding H, Wang J, Chan PS, Huang J. Prevalence and risk factors of colorectal cancer in Asia. Intest Res 2019;17:317-29.

2. Rex DK, Boland CR, Dominitz JA, Giardiello FM, Johnson DA, Kaltenbach T, et al. Colorectal cancer screening: recommendations for physicians and patients from the U.S. Multi-Society Task Force on colorectal cancer. Am J Gastroenterol 2017;112:1016-30.

3. Korean Statistical Information Service. Cancer incident cases and incidence rates by site ( 24 items), sex, age group [Internet]. Daejeon (KR): KOSIS; 2021 [cited 2021 Apr 14]. Available from: http://kosis.kr/statHtml/statHt$\mathrm{ml}$.do?orgld=117\&tblld=DT_117N_A00023\&conn_path= I2\&language $=e n$.

4. Bailey CE, Hu CY, You YN, Bednarski BK, Rodriguez-Bigas MA, Skibber JM, et al. Increasing disparities in the age-related incidences of colon and rectal cancers in the United States, 1975-2010. JAMA Surg 2015;150:17-22.

5. Inra JA, Syngal S. Colorectal cancer in young adults. Dig Dis Sci 2015;60:722-33.

6. Gupta S, Lieberman D, Anderson JC, Burke CA, Dominitz $J A$, Kaltenbach T, et al. Recommendations for follow-up after colonoscopy and polypectomy: a consensus update by the US Multi-Society Task Force on colorectal cancer. Am J Gastroenterol 2020;115:415-34.

7. Imperiale TF, Wagner DR, Lin CY, Larkin GN, Rogge JD, Ransohoff DF. Results of screening colonoscopy among persons 40 to 49 years of age. N Engl J Med 2002;346:1781-5.

8. Byeon JS, Yang SK, Kim TI, Kim WH, Lau JY, Leung WK, et al. Colorectal neoplasm in asymptomatic Asians: a prospective multinational multicenter colonoscopy survey. Gastrointest Endosc 2007;65:1015-22.

9. Park HW, Byeon JS, Yang SK, Kim HS, Kim WH, Kim TI, et al. Colorectal neoplasm in asymptomatic average-risk
Koreans: the KASID Prospective Multicenter Colonoscopy Survey. Gut Liver 2009;3:35-40.

10. Hong SN, Kim JH, Choe WH, Han HS, Sung IK, Park HS, et al. Prevalence and risk of colorectal neoplasms in asymptomatic, average-risk screenees 40 to 49 years of age. Gastrointest Endosc 2010;72:480-9.

11. Chung SJ, Kim YS, Yang SY, Song JH, Park MJ, Kim JS, et al. Prevalence and risk of colorectal adenoma in asymptomatic Koreans aged 40-49 years undergoing screening colonoscopy. J Gastroenterol Hepatol 2010;25:519-25.

12. Chang LC, Wu MS, Tu CH, Lee YC, Shun CT, Chiu HM. Metabolic syndrome and smoking may justify earlier colorectal cancer screening in men. Gastrointest Endosc 2014; 79:961-9.

13. Jung YS, Ryu S, Chang Y, Yun KE, Park JH, Kim HJ, et al. Risk factors for colorectal neoplasia in persons aged 30 to 39 years and 40 to 49 years. Gastrointest Endosc 2015; 81:637-45.

14. Kwak JY, Kim KM, Yang HJ, Yu KJ, Lee JG, Jeong YO, et al. Prevalence of colorectal adenomas in asymptomatic young adults: a window to early intervention? Scand J Gastroenterol 2016;51:731-8.

15. Koo JE, Kim KJ, Park HW, Kim HK, Choe JW, Chang HS, et al. Prevalence and risk factors of advanced colorectal neoplasms in asymptomatic Korean people between 40 and 49years of age. J Gastroenterol Hepatol 2017;32:98-105.

16. Kim KO, Yang HJ, Cha JM, Shin JE, Kim HG, Cho YS, et al. Risks of colorectal advanced neoplasia in young adults versus those of screening colonoscopy in patients aged 50 to 54 years. J Gastroenterol Hepatol 2017;32:1825-31.

17. Kim NH, Jung YS, Yang HJ, Park SK, Park JH, Park DI, et al. Prevalence of and risk factors for colorectal neoplasia in asymptomatic young adults (20-39 years old). Clin Gastroenterol Hepatol 2019;17:115-22.

18. Butterly LF, Siegel RL, Fedewa S, Robinson CM, Jemal A, Anderson JC. Colonoscopy outcomes in average-risk screening equivalent young adults: data from the New Hampshire Colonoscopy Registry. Am J Gastroenterol 2021;116:171-9.

19. Jung YS, Park CH, Kim NH, Lee MY, Park DI. Impact of age on the risk of advanced colorectal neoplasia in a young population: an analysis using the predicted probability model. Dig Dis Sci 2017;62:2518-25.

20. Kim JY, Choi S, Park T, Kim SK, Jung YS, Park JH, et al. Development and validation of a scoring system for advanced colorectal neoplasm in young Korean subjects less than age 50 years. Intest Res 2019;17:253-64.

21. Jung YS, Yun KE, Chang Y, Ryu S, Park DI. Risk factors such 
as male sex, smoking, metabolic syndrome, obesity, and fatty liver do not justify screening colonoscopies before age 45. Dig Dis Sci 2016;61:1021-7.

22. Park CH, Kim NH, Park JH, Park DI, Sohn Cl, Jung YS. Individualized colorectal cancer screening based on the clinical risk factors: beyond family history of colorectal cancer. Gastrointest Endosc 2018;88:128-35.

23. Kim NH, Park JH, Park DI, Sohn Cl, Choi K, Jung YS. The fecal immunochemical test has high accuracy for detecting advanced colorectal neoplasia before age 50. Dig Liver Dis 2017;49:557-61.

24. Jung YS, Park CH, Kim NH, Park JH, Park DI, Sohn Cl. Colorectal cancer screening with the fecal immunochemical test in persons aged 30 to 49 years: focusing on the age for commencing screening. Gastrointest Endosc 2017;86: 892-9.

25. Chen $\mathrm{CH}$, Tsai MK, Wen CP. Extending colorectal cancer screening to persons aged 40 to 49 years with immunochemical fecal occult blood test: a prospective cohort study of 513,283 individuals. J Clin Gastroenterol 2016; 50:761-8.

26. Wolf AMD, Fontham ETH, Church TR, Flowers CR, Guerra $\mathrm{CE}$, LaMonte SJ, et al. Colorectal cancer screening for average-risk adults: 2018 guideline update from the American Cancer Society. CA Cancer J Clin 2018;68:250-81.

27. Jung YS, Park CH, Kim NH, Park JH, Park DI, Sohn Cl. A combination of clinical risk stratification and fecal immunochemical test is useful for identifying persons with high priority of early colonoscopy. Dig Liver Dis 2018;50: 254-9.

28. Yeoh KG, Ho KY, Chiu HM, Zhu F, Ching JY, Wu DC, et al. The Asia-Pacific Colorectal Screening score: a validated tool that stratifies risk for colorectal advanced neoplasia in asymptomatic Asian subjects. Gut 2011;60:1236-41.

29. Park CH, Jung YS, Kim NH, Park JH, Park DI, Sohn Cl. Usefulness of risk stratification models for colorectal cancer based on fecal hemoglobin concentration and clinical risk factors. Gastrointest Endosc 2019;89:1204-11.

30. Auge JM, Pellise M, Escudero JM, Hernandez C, Andreu M, Grau J, et al. Risk stratification for advanced colorectal neoplasia according to fecal hemoglobin concentration in a colorectal cancer screening program. Gastroenterology 2014;147:628-36.

31. Kim NH, Kwon MJ, Kim HY, Lee T, Jeong SH, Park DI, et al. Fecal hemoglobin concentration is useful for risk stratification of advanced colorectal neoplasia. Dig Liver Dis 2016; 48:667-72.

32. Liao CS, Lin YM, Chang HC, Chen YH, Chong LW, Chen CH, et al. Application of quantitative estimates of fecal hemoglobin concentration for risk prediction of colorectal neoplasia. World J Gastroenterol 2013;19:8366-72.

33. Cha JM, La Selva D, Kozarek RA, Gluck M, Ross A, Lin OS. Young patients with sporadic colorectal adenomas: current endoscopic surveillance practices and outcomes. Gastrointest Endosc 2018;88:818-25.

34. Yang DH, Hong SN, Kim YH, Hong SP, Shin SJ, Kim SE, et al. Korean guidelines for postpolypectomy colonoscopy surveillance. Clin Endosc 2012;45:44-61.

35. Martinez ME, Baron JA, Lieberman DA, Schatzkin A, Lanza E, Winawer SJ, et al. A pooled analysis of advanced colorectal neoplasia diagnoses after colonoscopic polypectomy. Gastroenterology 2009;136:832-41.

36. Kim NH, Jung YS, Park JH, Park DI, Sohn Cl. Risk of developing metachronous advanced colorectal neoplasia after colonoscopic polypectomy in patients aged 30 to 39 and 40 to 49 years. Gastrointest Endosc 2018;88:715-23.

37. Kim HG, Cho YS, Cha JM, Shin JE, Kim KO, Yang HJ, et al. Risk of metachronous neoplasia on surveillance colonoscopy in young patients with colorectal neoplasia. Gastrointest Endosc 2018;87:666-73.

38. Nagpal SJS, Mukhija D, Sanaka M, Lopez R, Burke CA. Metachronous colon polyps in younger versus older adults: a case-control study. Gastrointest Endosc 2018;87:657-65.

39. Anderson JC, Robinson CM, Butterly LF. Young adults and metachronous neoplasia: risks for future advanced adenomas and large serrated polyps compared with older adults. Gastrointest Endosc 2020;91:669-75.

40. Laish I, Katz L, Ben-Horin S, Yablecovitch D, Naftali T. Risk of metachronous neoplasia on surveillance colonoscopy among young and older patients after polypectomy. Dig Liver Dis 2020;52:427-33. 